\title{
Molecular Modeling of Pathogenic Mutations in the Keratin 1B Domain
}

\author{
Alexander J. Hinbest ${ }^{1}$, Sherif A. Eldirany ${ }^{2}$, Minh Ho $^{3} \mathbb{D}$ and Christopher G. Bunick ${ }^{3,4, *(D)}$ \\ 1 Department of Molecular Biology and Biochemistry, Wesleyan University, Middletown, CT 06459, USA; \\ ahinbest@wesleyan.edu \\ 2 Yale School of Medicine, Yale University, New Haven, CT 06520, USA; sherif.eldirany@yale.edu \\ 3 Department of Dermatology, Yale University, New Haven, CT 06520, USA; minh.ho@yale.edu \\ 4 Department of Molecular Biophysics and Biochemistry, Yale University, New Haven, CT 06520, USA \\ * Correspondence: Christopher.bunick@yale.edu; Tel.: +1-203-785-4092
}

Received: 3 August 2020; Accepted: 7 September 2020; Published: 10 September 2020

\begin{abstract}
Keratin intermediate filaments constitute the primary cytoskeletal component of epithelial cells. Numerous human disease phenotypes related to keratin mutation remain mechanistically elusive. Our recent crystal structures of the helix 1B heterotetramer from keratin 1/10 enabled further investigation of the effect of pathologic $1 \mathrm{~B}$ domain mutations on keratin structure. We used our highest resolution keratin 1B structure as a template for homology-modeling the $1 \mathrm{~B}$ heterotetramers of keratin 5/14 (associated with blistering skin disorders), keratin 8/18 (associated with liver disease), and keratin 74/28 (associated with hair disorder). Each structure was examined for the molecular alterations caused by incorporating pathogenic 1B keratin mutations. Structural modeling indicated keratin 1B mutations can harm the heterodimer interface (R265PK5, L311R $\left.{ }^{\mathrm{K} 5}, \mathrm{R} 211 \mathrm{P}^{\mathrm{K} 14}, \mathrm{I}^{\mathrm{K}} 150 \mathrm{~V}^{\mathrm{K} 18}\right)$, the tetramer interface $\left(\mathrm{F} 231 \mathrm{~L}^{\mathrm{K} 1}, \mathrm{~F} 274 \mathrm{~S}^{\mathrm{K} 74}\right)$, or higher-order interactions needed for mature filament formation (S233L $\left.\mathrm{K}^{\mathrm{K}}, \mathrm{L} 311 \mathrm{R}^{\mathrm{K} 5}, \mathrm{Q} 169 \mathrm{E}^{\mathrm{K} 8}, \mathrm{H} 128 \mathrm{~L}^{\mathrm{K} 18}\right)$. The biochemical changes included altered hydrophobic and electrostatic interactions, and altered surface charge, hydrophobicity or contour. Together, these findings advance the genotype-structurotype-phenotype correlation for keratin-based human diseases.
\end{abstract}

Keywords: keratin; intermediate filament; structure; modeling; skin disease; liver disease; epidermolysis bullosa; cytoskeleton; mutation

\section{Introduction}

Intermediate filaments (IFs) work with actin microfilaments and microtubules to provide essential cytoskeleton functions within eukaryotic cells. IFs are aptly named because their diameter $(\sim 10 \mathrm{~nm})$ is in between that of actin $(\sim 4-5 \mathrm{~nm})$ and microtubules $(\sim 25 \mathrm{~nm})$ [1]. There are six types of IFs [2], with type I and II representing keratins. The 54 keratin genes outnumber all the other IF types combined. Keratins are obligate heterodimers, with one type I keratin dimerizing in register and parallel with one type II keratin [3]. Parallel heterodimers then form anti-parallel tetramers, which serve as the building block for mature IFs.

Keratins are differentially expressed across human tissues, providing unique biological functions to support the host organism. For example, keratins 5 and 14 (K5/14) and K1/10 are expressed in stratified epithelia. K5/14 are the primary keratins in basal layer keratinocytes, whereas K1/10 are the primary suprabasal IF proteins in differentiating keratinocytes of the epidermis. Hard keratins (K25-86), found in hair and nails, utilize abundant cysteine cross-linking to form more rigid filaments than epithelial keratin IFs (K1-K24) [4]. 
Keratins support human health, as exemplified by the fact that more than 80 human IF-related diseases (termed IF-pathies [5]) exist. For example, different keratin mutations are responsible for blistering skin disorders (e.g., epidermolysis bullosa simplex, EBS), keratodermas (e.g., epidermolytic palmoplantar keratoderma, EPPK), hair and nail defects (e.g., pachyonychia congenita), and liver disease (e.g., cryptogenic cirrhosis) [6]. Keratins have also been linked to cancer, corneal dystrophy, and pancreatitis [7]. IF mutations vary in type: deletion, insertion, nonsense, and missense. Efforts have been made to correlate a patient's keratin genotype with clinical phenotype for these diseases [7-13]. Understanding how keratin genotype impacts the molecular structure of keratin filaments is also important, and we have termed this concept genotype-structurotype-phenotype correlation [14,15].

Keratins share a common protein organization: flexible, glycine- and serine-rich head and tail domains bookend a highly-conserved central coiled-coil rod domain, itself comprised of 1A, 1B, 2A, and $2 \mathrm{~B}$ subdomains. We recently determined two keratin 1/10 1B domain crystal structures [16]. The first was a $3.0 \AA$ A resolution structure of wild-type K1/K10-1B (Protein Data Bank (PDB) ID 6EC0), and the second was a $2.4 \AA$ resolution structure of $\mathrm{K} 1 / \mathrm{K} 10-1 \mathrm{~B}$ incorporating the $\mathrm{S} 233 \mathrm{~L}^{\mathrm{K} 1}$ mutation responsible for EPPK (PDB ID 6E2J). 1B domain structures of homomeric IF proteins have also been determined (vimentin, glial fibrillary acidic protein (GFAP), lamin A) [17-21]. The keratin structures represent the only heteromeric $1 \mathrm{~B}$ structures to date, and as such they are experimentally determined quality templates for modeling $1 \mathrm{~B}$ domains from other keratin pairs. Here, we used our highest resolution $\mathrm{K} 1 / \mathrm{K} 101 \mathrm{~B}$ structure to model $1 \mathrm{~B}$ domains of $\mathrm{K} 5 / \mathrm{K} 14, \mathrm{~K} 8 / \mathrm{K} 18$, and $\mathrm{K} 74 / \mathrm{K} 28$ in order to evaluate the structural alterations associated with pathogenic keratin missense mutations in this region. In particular, we wanted to ascertain whether the mutations would impact the dimer, tetramer, or high-order assembly of the keratins, and how the mutations would affect the molecular surface properties (charge, hydrophobicity, contour) of the keratins.

\section{Results}

\subsection{Identification of Keratin $1 B$ Mutations}

The Human Intermediate Filament Database (HIFD) [6] was analyzed to find all missense mutations in the $1 \mathrm{~B}$ region of keratins. We identified 15 mutations: 9 missense, 3 nonsense, 2 leading to frameshift, and 1 in-frame deletion (indel) (Table 1). To predict the potential impact of the missense mutations on keratin structure and function, we utilized Polyphen-2 to analyze the primary keratin sequences [22]. Six out of nine keratin missense mutations had a polyphen score classified as possibly or probably damaging $\left(\mathrm{F} 231 \mathrm{~L}^{\mathrm{K} 1}, \mathrm{~S} 233 \mathrm{~L}^{\mathrm{K} 1}, \mathrm{R} 265 \mathrm{P}^{\mathrm{K} 5}, \mathrm{~L} 311 \mathrm{R}^{\mathrm{K} 5}\right.$, R211P $\mathrm{P}^{\mathrm{K} 14}, \mathrm{~F} 274 \mathrm{~S}^{\mathrm{K} 74}$ ) (Table 1). The other three mutations $\left(\mathrm{Q} 169 \mathrm{E}^{\mathrm{K} 8}, \mathrm{H} 128 \mathrm{~L}^{\mathrm{K} 18}, \mathrm{I} 150 \mathrm{~V}^{\mathrm{K} 18}\right)$ were predicted to be benign. 
Table 1. Keratin 1B domain mutations identified from the Human Intermediate Filament Database. Fifteen DNA and protein mutations are listed, with 9 missense mutations that were modeled in this study. The Polyphen-2 algorithm was used to generally predict a mutation effect on the keratin. "Disease Mechanism" depicts the hypothesized or experimentally validated filamentous structural changes believed to contribute to the disease phenotype. Abbreviations: (N)EPPK, (Non)-epidermal Palmoplantar Keratoderma; BCIE, Bullous Congenital Ichthyosiform Erythroderma; EHK, Epidermolytic Hyperkeratosis; (R)EBS-K/WC, (Recessive) Epidermolysis Bullosa Simplex: Koebner or Weber-Cockayne subtypes; CIEH, Cyclic Ichthyosis with Epidermolytic Hyperkeratosis; ADWH, Autosomal-Dominant Woolly Hair; LOF, Loss of Function.

\begin{tabular}{|c|c|c|c|c|c|c|c|c|c|}
\hline DNA Mutation & Protein Mutation & Protein & $\begin{array}{c}\text { Hetero } \\
\text { Pair }\end{array}$ & Mutation Type & PolyphnScore & PolyphenPrediction & $\begin{array}{c}\text { Disease } \\
\text { Association }\end{array}$ & $\begin{array}{c}\text { Disease } \\
\text { Mechanism }\end{array}$ & References \\
\hline c.693T $>\mathrm{G}$ & p.Phe231Leu & K1 & $\mathrm{K} 1 / 10$ & Missense & 0.971 & Probably Damaging & NEPPK & $\begin{array}{c}\text { Disrupts 1B } \\
\text { knob-pocket } \\
\text { interaction }\end{array}$ & [23] \\
\hline c. $698 \mathrm{C}>\mathrm{T}$ & p.Ser233Leu & $\mathrm{K} 1$ & $\mathrm{~K} 1 / 10$ & Missense & 0.704 & Possibly Damaging & $\begin{array}{c}\text { EPPK, } \\
\text { NEPPK, } \\
\text { BCIE/EHK }\end{array}$ & $\begin{array}{l}\text { Tonotubular filament } \\
\text { formation }\end{array}$ & {$[16,23-25]$} \\
\hline c.794G $>C$ & p.Arg265Pro & K5 & $\mathrm{K} 5 / 14$ & Missense & 0.975 & Probably Damaging & EBS-K & Unknown & [26] \\
\hline c.932T $>\mathrm{G}$ & p.Leu311Arg & $\mathrm{K} 5$ & $\mathrm{~K} 5 / 14$ & Missense & 0.908 & Possibly Damaging & EBS-WC & Unknown & [27] \\
\hline c. $475 \mathrm{C}>\mathrm{G}$ & p.Gln169Glu & K8 & $\mathrm{K} 8 / 18$ & Missense & 0.171 & Benign & $\begin{array}{l}\text { Cryptogenic } \\
\text { cirrhosis }\end{array}$ & Unknown & {$[28]$} \\
\hline c. $846 \mathrm{~T}>\mathrm{A}$ & p.Tyr282X & K10 & $\mathrm{K} 1 / 10$ & $\begin{array}{c}\text { Nonsense } \\
\text { (truncation) }\end{array}$ & N/A & $\mathrm{N} / \mathrm{A}$ & CIEH & $\begin{array}{c}\mathrm{LOF}(\mathrm{K} 10 \mathrm{~K} / \mathrm{O}), \\
\text { aggregated K1, } \\
\text { compensatory } \\
\text { upregulation of K14 } \\
\text { \& K17 }\end{array}$ & [29] \\
\hline c. $526-2 \mathrm{~A}>\mathrm{C}$ & $\begin{array}{l}\text { p.[Ile176ValfsX2, } \\
\text { Ile176ProfsX30] }\end{array}$ & K14 & K5/14 & $\begin{array}{l}\text { Frame-shift } \\
\text { (truncation) }\end{array}$ & N/A & N/A & REBS, REBS-K & $\begin{array}{l}\text { Basal K14 IF loss, } \\
\text { compensatory K15 } \\
\text { protofilaments }\end{array}$ & [30-32] \\
\hline c. $[612 \mathrm{~T}>\mathrm{A}]+[612 \mathrm{~T}>\mathrm{A}]$ & p. $[$ Tyr204X]+[Tyr204X] & K14 & K5/14 & $\begin{array}{c}\text { Nonsense } \\
\text { (truncation) }\end{array}$ & $\mathrm{N} / \mathrm{A}$ & $\mathrm{N} / \mathrm{A}$ & REBS-K & $\begin{array}{c}\text { "Natural K14 K/O", } \\
\text { Basal K14 IF loss, } \\
\text { insoluble keratin } \\
\text { aggregation }\end{array}$ & {$[33,34]$} \\
\hline c. $632 \mathrm{G}>\mathrm{C}$ & p.Arg211Pro & K14 & $\mathrm{K} 5 / 14$ & Missense & 0.999 & Probably Damaging & EBS-WC & Unknown & [35] \\
\hline c.740_748delCCTACCTGAinsGAA & p.Ala247_Lys250delinsGlu & K14 & $\mathrm{K} 5 / 14$ & Indel (in-frame) & $\mathrm{N} / \mathrm{A}$ & $\mathrm{N} / \mathrm{A}$ & EBS-WC & Unknown & [36] \\
\hline c.744delCinsAG & p.Tyr248X & K14 & K5/14 & $\begin{array}{c}\text { Nonsense } \\
\text { (truncation) }\end{array}$ & N/A & $\mathrm{N} / \mathrm{A}$ & REBS-K & $\begin{array}{l}\text { "Natural K14 K/O", } \\
\text { Basal K14 IF loss, } \\
\text { insoluble keratin } \\
\text { aggregation }\end{array}$ & [37] \\
\hline
\end{tabular}


Table 1. Cont.

\begin{tabular}{|c|c|c|c|c|c|c|c|c|c|}
\hline DNA Mutation & Protein Mutation & Protein & $\begin{array}{c}\text { Hetero } \\
\text { Pair }\end{array}$ & Mutation Type & PolyphnScore & PolyphenPrediction & $\begin{array}{c}\text { Disease } \\
\text { Association }\end{array}$ & $\begin{array}{c}\text { Disease } \\
\text { Mechanism }\end{array}$ & References \\
\hline c.749delA & p.Lys250ArgfsX8 & K14 & $\mathrm{K} 5 / 14$ & Deletion (frame-shift) & $\mathrm{N} / \mathrm{A}$ & $\mathrm{N} / \mathrm{A}$ & REBS & $\begin{array}{l}\text { Absent K14 } \\
\text { expression }\end{array}$ & [38] \\
\hline$c .383 \mathrm{~A}>\mathrm{T}$ & p.His128Leu & K18 & $\mathrm{K} 8 / 18$ & Missense & 0.014 & Benign & $\begin{array}{c}\text { Cryptogenic } \\
\text { cirrhosis }\end{array}$ & $\begin{array}{c}\text { Abnormal IF } \\
\text { assembly }\end{array}$ & [39] \\
\hline c. $448 \mathrm{~A}>\mathrm{G}$ & p.Ile150Val & K18 & K8/18 & Missense & 0.247 & Benign & Liver disease & Unknown & [40] \\
\hline c. $821 \mathrm{~T}>\mathrm{C}$ & p.Phe274Ser & K74 & $\begin{array}{c}\text { K74/14 or } \\
\text { K74/28 }\end{array}$ & Missense & 0.998 & Probably Damaging & $\begin{array}{c}\text { Ectodermal } \\
\text { Dysplasia, } \\
\text { Pure } \\
\text { Hair-Nail } \\
\text { Type, ADWH }\end{array}$ & $\begin{array}{c}\text { Disrupts 1B } \\
\text { knob-pocket } \\
\text { interaction }\end{array}$ & {$[16,41]$} \\
\hline
\end{tabular}




\subsection{K1/K10 1B Missense Mutations Associated with Keratodermas}

We previously determined the crystal structure of $\mathrm{K} 1 / \mathrm{K} 10$ containing $\mathrm{S} 233 \mathrm{~L}^{\mathrm{K} 1}$ and also characterized the $1 \mathrm{~B}$ domain harboring S233L $\mathrm{L}^{\mathrm{K} 1}$ by multi-angle light scattering (MALS) [16]. This particular mutation is associated with epidermolytic palmoplantar keratoderma (EPPK) and histologically has the key finding of tonotubular keratin [24,42]. The structure identified that S233L K1 caused a new hydrophobic patch on the molecular surface of the K1/K10 dimer, and MALS demonstrated it also caused keratin aggregation in solution. The structure also showed that the aberrant leucine residue directly participated in inter-tetramer contacts promoting octameric assembly between K1/K10 tetramers (Figure 1a). How this excess hydrophobicity on the K1/K10 dimer surface leads to tubule formation for full-length K1/K10 remains unclear, but the tendency for hydrophobicity-driven aggregation is established.

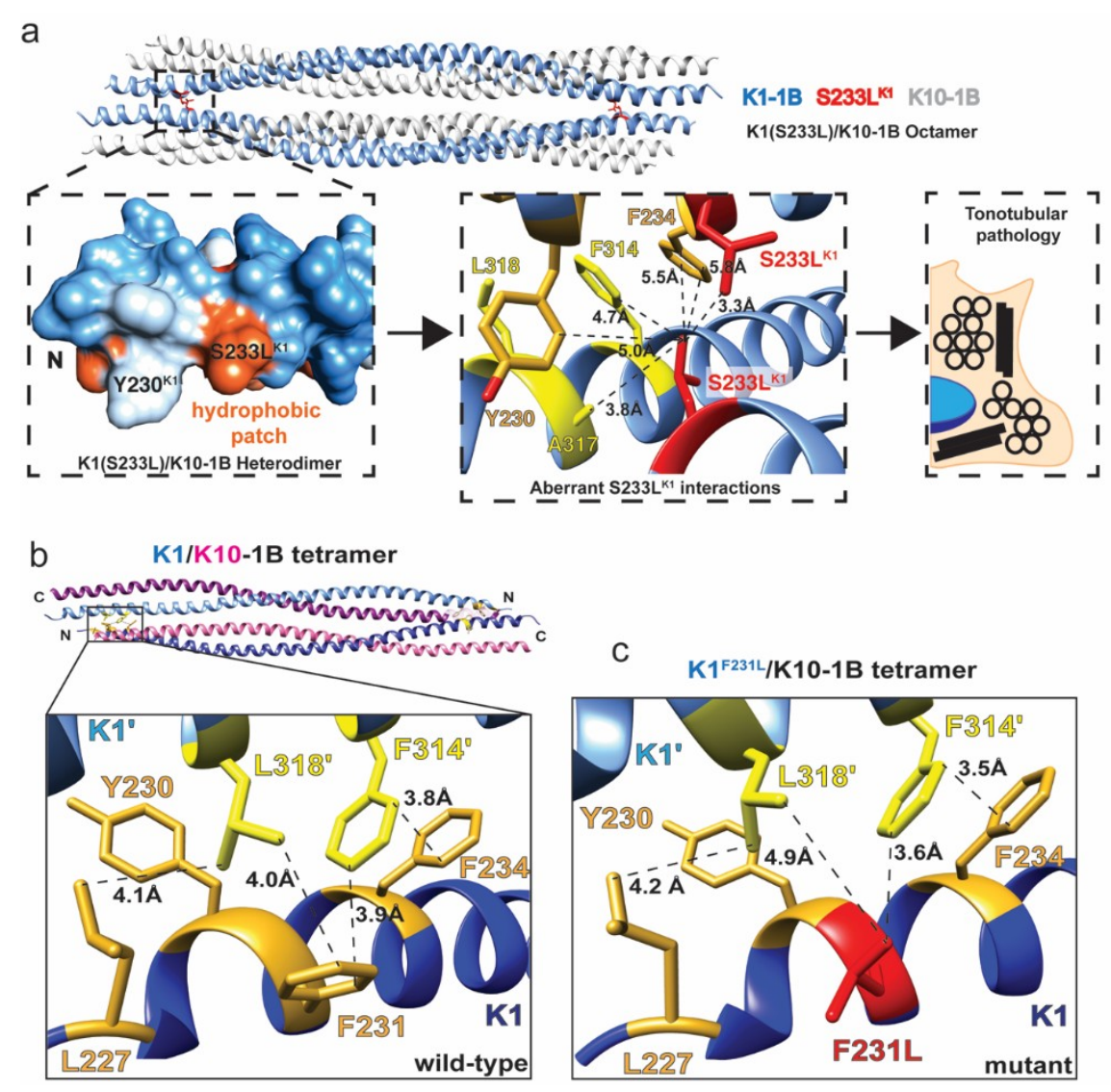

Figure 1. Keratin $11 \mathrm{~B}$ mutations affect the oligomeric state of the K1/K10-1B heterocomplex. (a) The crystal structure of the $\mathrm{K} 1 \mathrm{~S} 233 \mathrm{~L} / \mathrm{K} 10-1 \mathrm{~B}$ domain (PDB ID 6E2J) is an octamer composed of two tetramers (top). A surface-exposed hydrophobic patch is created by the serine to leucine mutation (left), resulting in the leucine making multiple aberrant hydrophobic interactions between tetramers (center). Histologically, this mutation results in tonotubular keratin, a more aggregated form than wild-type tonofilaments (right). (b) The crystal structure of the wild-type K1/K10-1B domain (PDB ID 6E2J) is a tetramer composed of anti-parallel dimers. A key interaction occurs between heterodimers: K1 residues comprised of an anchoring knob from one dimer (F314, L318, yellow) bind into a hydrophobic pocket on the surface of the other dimer (L227, Y230, F231, F234, gold). (c) The F231L mutation occurs in one of the key hydrophobic pocket residues in $\mathrm{K} 1$ (red). Modeling of this mutation reveals disruption of the knob-pocket interaction, likely leading to tetramer destabilization.

In contrast to S233L $\mathrm{L}^{\mathrm{K}}$, F231 $\mathrm{L}^{\mathrm{K} 1}$ alters the tetrameric interface between two $\mathrm{K} 1 / \mathrm{K} 10$ dimers at the anchoring knob-hydrophobic pocket assembly mechanism [16]. F231L $\mathrm{K}^{\mathrm{i}}$ is associated with non-epidermolytic palmoplantar keratoderma (NEPPK) [23]. In the wild-type K1/K10 complex, 
F231 ${ }^{\mathrm{K} 1}$ makes molecular contacts with F314 and L318 from the partner K1 molecule to help form the $\mathrm{K} 1 / \mathrm{K} 10$ tetramer (Figure $1 \mathrm{~b}$ ). Modeling of F231L $\mathrm{L}^{\mathrm{1}}$ suggests there is an increase in the contact distance between the mutant L231 and L318' as well as a loss of the aromatic-aromatic interactions by F314' (Figure 1c). These molecular changes caused by F231L ${ }^{\mathrm{K} 1}$ likely destabilize the keratin $1 \mathrm{~B}$ tetrameric interface, which in turn affects mature filament formation and function.

\subsection{K5/K14 1B Missense Mutations Cause Epidermolysis Bullosa Simplex}

Mutations in keratins 5 and 14 are commonly associated with EBS, but the vast majority of these mutations lie within the $1 \mathrm{~A}$ or $2 \mathrm{~B}$ subdomains [13]. Of the 9 unique mutations we identified in the $1 \mathrm{~B}$ subdomain (Table 1), three were in K5/K14: two K5 (R265P, L311R) and one K14 (R211P) missense mutations that are documented to cause EBS (Figure 2).

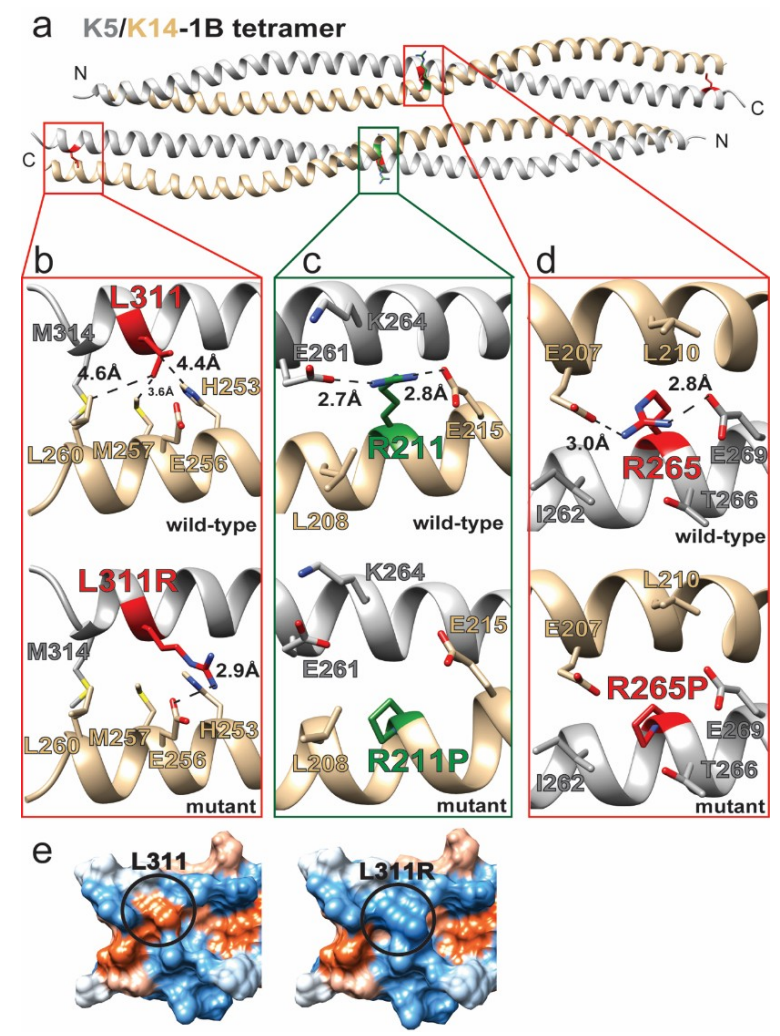

Figure 2. Keratin 5 and keratin $141 \mathrm{~B}$ mutations destabilize the K5/K14 heterodimer. (a) The K5/K14-1B tetramer was generated by homology modeling using the crystal structure of K1/K10-1B (PDB ID 6E2J) as a template. Two of the three identified missense mutations occur in the middle of the domain and the other at the carboxy-terminal end. (b) The $\mathrm{L} 311 \mathrm{R}^{\mathrm{K} 5}$ mutation disrupts intra-dimeric hydrophobic interactions with nearby K14 residues and may cause an aberrant electrostatic interaction (with E256 ${ }^{\mathrm{K} 14}$ ). (c) $\mathrm{R} 211 \mathrm{P}^{\mathrm{K} 14}$ disrupts two electrostatic interactions (with $\mathrm{E} 261^{\mathrm{K} 5}$ and $\mathrm{E} 215^{\mathrm{K} 14}$ ) at the dimer interface. (d) $\mathrm{R} 265 \mathrm{P}^{\mathrm{K} 5}$ disrupts two electrostatic interactions (with $\mathrm{E} 269^{\mathrm{K} 5}$ and $\mathrm{E} 207^{\mathrm{K} 14}$ ) at the dimer interface. (e) The comparison of hydrophobic surfaces (orange $=$ hydrophobic, white $=$ neutral, blue $=$ polar) of the wild-type (left) and L311R ${ }^{\mathrm{K} 5}$ (right) K5/K14-1B C-terminus demonstrates that the mutation eliminates a surface-exposed hydrophobic patch.

$\mathrm{R} 211 \mathrm{P}^{\mathrm{K} 14}$ was identified during screening of 27 German EBS patients; the individual from which the mutation was identified also suffered from palmoplantar symptoms [35]. The authors hypothesized that proline incorporation due to $\mathrm{R} 211 \mathrm{P}^{\mathrm{K} 14}$ led to helix kinking, which is a known structural property of proline [43]. R211 ${ }^{\mathrm{K} 14}$ lies in the center of the K5/14 1B domain at the heterodimer interface (Figure 2a). Modeling of wild-type K5/14 1B shows R211 forms electrostatic interactions or salt bridges with $\mathrm{E} 215^{\mathrm{K} 14}$ and $\mathrm{E} 261^{\mathrm{K} 5}$ (Figure 2c). By having intra-K14 and inter-K5 interactions, R211 ${ }^{\mathrm{K} 14}$ provides 
stabilization to the $\mathrm{K} 5 / 141 \mathrm{~B}$ dimer interface. Mutation to proline eliminates the dual electrostatic/salt bridge interactions, in addition to kinking the K14 helix, thereby destabilizing the K5/14 heterodimer. $\mathrm{R} 265 \mathrm{P}^{\mathrm{K} 5}$ is a mutation identified in Korean EBS patients [26] and located in the middle of the 1B domain (Figure 2a). The structural model of K5/14 1B demonstrates that R265 ${ }^{\mathrm{K} 5}$, like R211 ${ }^{\mathrm{K} 14}$, forms electrostatic interactions or salt bridges with residues that are intra-strand (E269 ${ }^{\mathrm{K} 5}$ ) as well as opposite dimer strand (E207 ${ }^{\mathrm{K} 14}$ ) (Figure 2d). Mutation R265 $\mathrm{P}^{\mathrm{K} 5}$ eliminates these important dual interactions that stabilize the $\mathrm{K} 5 / 14$ heterodimer, in addition to the expected helix kinking.

$\mathrm{L} 311 \mathrm{R}^{\mathrm{K} 5}$ was one of several $\mathrm{K} 5 / 14$ mutations detected from sequencing of 10 Israeli patients suffering from EBS [27]. L311 ${ }^{\mathrm{K} 5}$ is located at the C-terminus of the K5/14 $1 \mathrm{~B}$ heterodimer, where it makes hydrophobic interactions in the dimer interface with K14 residues H253, M257, and L260 (Figure 2b). L311R ${ }^{\mathrm{K} 5}$ mutation leads to the substitution of a bulkier basic residue that disrupts hydrophobic interactions and may generate new electrostatic interactions with E256 ${ }^{\mathrm{K} 14}$. The molecular surface properties of $\mathrm{K} 5 / 14 \mathrm{1B}$ are also changed, notably the loss of a surface-exposed hydrophobic patch at the C-terminus of the K5/14 1B heterodimer (Figure 2e). The loss of surface hydrophobicity likely disrupts higher-order filament interactions needed for mature IF formation.

\subsection{Structural Alterations in K8/K18 1B Are Associated with Liver Disease}

Keratins 8 and 18 (K8/18) are predominantly expressed in "simple" epithelia, and mutations in them are frequently associated with liver disease (Table 1 and Figure 3) [44]. Q169E ${ }^{\mathrm{K} 8}$ was identified during sequencing of 162 hemochromatosis patients as part of an analysis of K8/18 intron mutations associated with hereditary hemochromatosis or liver fibrosis [28]. Q169 ${ }^{\mathrm{K} 8}$ is located in the central aspect of the K8/18 1B domain as part of the heterodimer interface (Figure 3a). It makes local van der Waals interactions with $\mathrm{L}_{165}{ }^{\mathrm{K} 8}$ and $\mathrm{Q} 153^{\mathrm{K} 18}$ (Figure 3c). Q169E ${ }^{\mathrm{K} 8}$ does not appear to significantly alter the local heterodimer packing, although the $\mathrm{OE} 2$ atom on $\mathrm{Q} 169 \mathrm{E}^{\mathrm{K} 8}$ might form a hydrogen bond with the $\mathrm{Q} 153^{\mathrm{K} 18} \mathrm{NE} 2$ atom. The larger effect of $\mathrm{Q} 169 \mathrm{E}^{\mathrm{K} 8}$ is on the molecular surface, where the acidic nature of the K8/K18 1B dimer and tetramer is enhanced by the mutation (Figure 3e). This acidic patch created by Q169E ${ }^{\mathrm{K} 8}$ may disturb higher-order K8/K18 filament assembly.

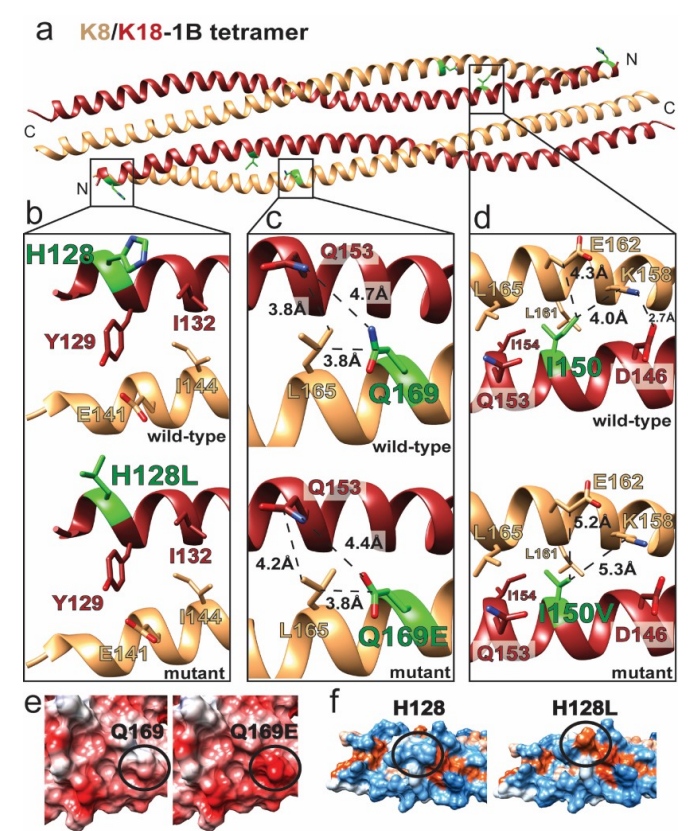

Figure 3. Keratin 8 and keratin 18 mutations alter intra-dimeric interactions and molecular surface properties. (a) The K8/K18-1B tetramer was generated by homology modeling using K1/K10-1B (PDB ID 6E2J) as a template. 
Missense mutated residues are identified in green. (b) The H128L ${ }^{\mathrm{K} 18}$ mutation does not disrupt intra-dimeric or tetrameric interactions. (c) $\mathrm{Q} 169 \mathrm{E}^{\mathrm{K} 8}$ has limited impact on packing at the dimer interface. (d) $\mathrm{I} 150 \mathrm{~V}^{\mathrm{K} 18}$ preserves most hydrophobic interactions at the dimer interface but may destabilize a salt bridge at the dimer interface (between $\mathrm{K} 158^{\mathrm{K} 8}$ and $\mathrm{D} 146^{\mathrm{K} 18}$ ) by eliminating a contact with $\mathrm{K} 158^{\mathrm{K} 8}$. (e) Comparison of electrostatic surfaces (red = acidic, white = neutral, blue = basic) of the wild-type (left) and $\mathrm{Q} 169 \mathrm{E}^{\mathrm{K} 8}$ (right) K8/K18-1B tetramer demonstrates that the mutation enhances the surface acidity of the molecule. (f) The comparison of the hydrophobic surfaces (orange = hydrophobic, white $=$ neutral, blue $=$ polar) of the wild-type $\left(\mathrm{left}\right.$ ) and $\mathrm{H} 128 \mathrm{~L}^{\mathrm{K} 18}$ (right) K8/K18-1B tetramer demonstrates that the mutation introduces a surface-exposed hydrophobic patch.

$\mathrm{H} 128^{\mathrm{K} 18}$ is located at the $\mathrm{N}$-terminus of the $\mathrm{K} 8 / 181 \mathrm{~B}$ heterodimer (Figure 3a). It is solvent-exposed and does not contribute to the hydrophobic dimeric interface (Figure $3 \mathrm{~b}$ ). It also faces solvent in the $\mathrm{K} 8 / 181 \mathrm{~B}$ tetramer, suggesting that $\mathrm{H} 128 \mathrm{~L}^{\mathrm{K} 18}$ mutation does not destabilize the $\mathrm{K} 8 / 18$ dimer or tetramer, but rather alters the higher-order assembly of mature filaments. H128 $\mathrm{L}^{\mathrm{K} 18}$ correlated with liver cirrhosis in a study involving patients with K8 and K18 mutations [45]. Mapping of hydrophobic potential onto the molecular surface of the $\mathrm{K} 8 / 181 \mathrm{~B}$ tetramer demonstrated that $\mathrm{H} 128 \mathrm{~L}^{\mathrm{K} 18}$ creates a bulky surface-exposed hydrophobic patch (Figure 3f). This patch would occur at both ends of the $\mathrm{K} 8 / 181 \mathrm{~B}$ tetramer due to the antiparallel alignment between dimers.

$\mathrm{I} 150 \mathrm{~V}^{\mathrm{K} 18}$ is another K18 mutation associated with liver disease [40]. $\mathrm{I} 150^{\mathrm{K} 18}$ is located in the center of K8/18 1B at the heterodimer interface (Figure 3a). It makes several hydrophobic contacts to stabilize the dimer, including interactions with $\mathrm{I} 154^{\mathrm{K} 18}, \mathrm{~L} 161^{\mathrm{K} 8}$, and $\mathrm{L} 165^{\mathrm{K} 8}$. The CD1 atom of $\mathrm{I} 150^{\mathrm{K} 18}$ also interacts with the aliphatic portions of $\mathrm{K} 158^{\mathrm{K} 8}$ and $\mathrm{E} 162^{\mathrm{K} 8}$, which stabilizes $\mathrm{K} 158^{\mathrm{K} 8}$ so that it can make a salt bridge with $\mathrm{D} 146^{\mathrm{K} 18}$ (Figure $3 \mathrm{~d}$ ). $\mathrm{I}_{150 \mathrm{~V}^{\mathrm{K} 18}}$ preserves the core hydrophobic interactions with $\mathrm{I} 154^{\mathrm{K} 18}, \mathrm{~L} 161^{\mathrm{K} 8}$, and $\mathrm{L} 165^{\mathrm{K} 8}$, but loss of the $\mathrm{CD} 1$ atom likely destabilizes contacts with $\mathrm{K} 158^{\mathrm{K} 8}$ and $\mathrm{E} 162^{\mathrm{K} 8}$ and potentially compromises the $\mathrm{E} 162^{\mathrm{K} 8}-\mathrm{D} 146^{\mathrm{K} 18}$ salt bridge.

\subsection{Anchoring Knob Mutation in the Hard Keratin K74}

Keratin 74 (K74) is a type II IF protein whose obligate IF partner has yet to be unambiguously identified. Prior work showed that K74 can pair with K14 and K18 [46]. However, this is inconsistent with the fact that K74 is largely expressed in the inner root sheath (IRS) of hair, while K14 and K18 are expressed in basal keratinocytes and simple epithelia, respectively. There is evidence for K74 co-expression with K28 [47], which more closely aligns with the physiology of hair keratin IF formation (both are inner root sheath keratins). Therefore, we modeled the K74/28 1B heterotetramer (Figure 4).

F274S ${ }^{\mathrm{K} 74}$ was identified during sequencing of a consanguineous Pakistani family which had homozygous autosomal recessive pure hair and nail ectodermal dysplasia (PHNED) [41]. Patients with PHNED displayed loss of K74 when staining for expression in nail matrix, nail bed, and IRS of hair follicle, in addition to mouse hyponychium. With the available information at the time, it was hypothesized that $\mathrm{F} 274 \mathrm{~S}^{\mathrm{K} 74}$ would interfere with keratin hetero-dimerization. However, our recent crystal structures of $\mathrm{K} 1 / \mathrm{K} 101 \mathrm{~B}$ tetramers (wild-type and S233L $\mathrm{L}^{\mathrm{K} 1}$ ) demonstrated that the sequence position of $\mathrm{F} 274^{\mathrm{K} 74}$ forms part of the anchoring knob involved in the anchoring knob-hydrophobic pocket tetramer assembly mechanism (Figure $4 a, b$ ). This mechanism is important for $A_{11}$ tetramer formation (where $\mathrm{A}_{11}$ means the $1 \mathrm{~B}$ domains are antiparallel and aligned in-phase in the tetramer) and mature filament assembly [16]. 


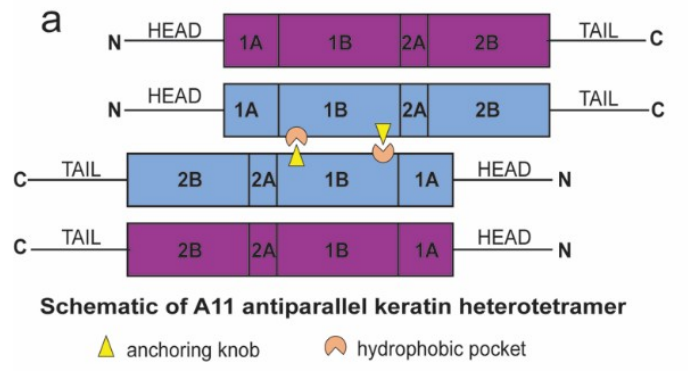

C

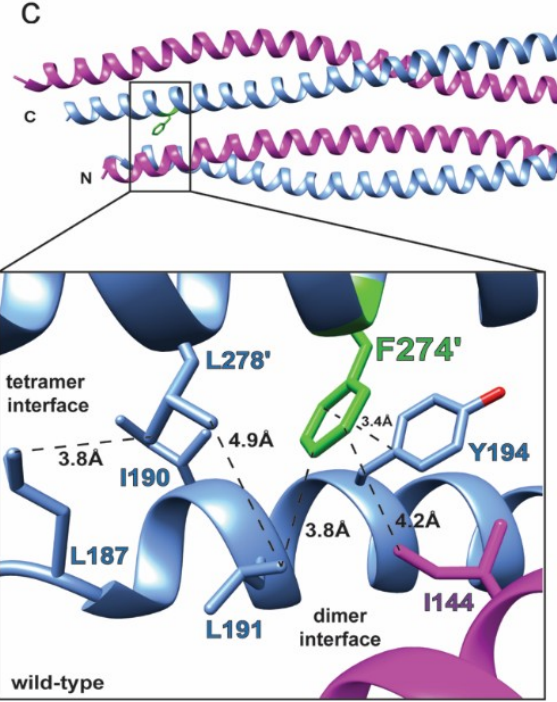

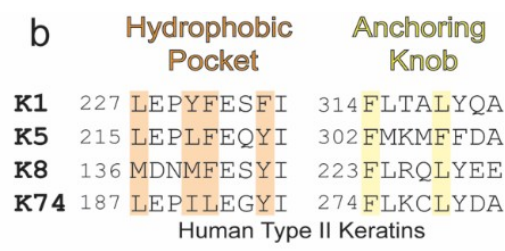

K10 195 DYSKYYKTI 282YLKKNHEE K14 161 DYSPYFKTI 248YLKKNHEE K18 125 DWSHYFKII 212FMKKNHEE K28 136 DYSRYHLTI 223YLKKNHEE

Human Type I Keratins
K74-1B K28-1B

$\mathrm{F} 274^{\mathrm{K}} \mathrm{4}$

K74/K28 1B Tetramer

Figure 4. The F274S $\mathrm{K}^{\mathrm{7} 4}$ mutation occurs in the anchoring knob and disrupts the tetramer interface. (a) The antiparallel keratin heterotetramer is stabilized by an anchoring knob-hydrophobic pocket interaction at both ends of the 1B domain. The "A11" alignment refers to the 1B domain of each heterodimer being in phase with each other in the tetramer state. (b) Knob and pocket residues are largely conserved in the type II keratins. These residues are not conserved in the type I keratins. (c,d) Modeling of the K74/K28-1B tetramer demonstrates loss of hydrophobic interactions in the knob-pocket mechanism as a result of the $\mathrm{F} 274 \mathrm{~S}^{\mathrm{K} 74}$ mutation.

In the structural model, K74 residues F274' and L278' form the anchoring knob at the K74/28 tetramer interface (Figure 4c). These residues pack into a hydrophobic pocket formed by the partner heterodimer (K74 residues L187, I190, L191, and Y194, and K28 residue I144). F274SK74 mutation dramatically alters the knob-pocket interaction site, eliminating hydrophobic interactions and aromatic-aromatic interactions (Figure 4d). This will destabilize the K74/28 1B tetramer at both ends. Thus, F274S ${ }^{\mathrm{K} 74}$ is likely to severely alter mature filament assembly based on prior electron microscopy data showing keratins $1 / 10$ and $8 / 18$ and vimentin $1 \mathrm{~B}$ knob mutations damage IF assembly [16].

\section{Discussion}

With 54 genes and differential expression by time and tissue type, keratins play a significant, but complex role in human physiology. Their medical relevance is exemplified by the high numbers of IF-related diseases associated with keratin mutation [5,7]. Their role in establishing and maintaining skin, hair, and nail aesthetics is also important. How keratins promote structural integrity within cells, facilitate protein interactions and signaling, and regulate tissue properties remains poorly understood at a molecular level. Their long, filamentous and insoluble nature contributes greatly to the difficulty in studying these proteins. Despite all the keratins known, only four out of 54 (K1, $\mathrm{K} 10, \mathrm{~K} 5, \mathrm{~K} 14)$ have experimentally determined atomic resolution structures [12-14,16,48]. In total, there are six crystal structures of human keratins. Only one of these contains a mutation (S233L ${ }^{\mathrm{K} 1}$ ) 
known to cause human disease [16]. Therefore, a better understanding of how keratin mutations alter protein structure is needed to help correlate patient genotype with phenotype: a paradigm we call genotype-structurotype-phenotype correlation [14,15].

In the spirit of this paradigm, the work here examines nine pathologic keratin mutations that occur within the $1 \mathrm{~B}$ subdomain of the keratin coiled-coil rod domain. Most keratin mutations associated with clinical disease are located in the $1 \mathrm{~A}$ and $2 \mathrm{~B}$ subdomains, with only a small number to date occurring in 1B. The molecular explanation for this difference is not clear, but evidence suggests the $1 \mathrm{~B}$ domain is critical for establishing the tetramer building block of IFs, whereas the $1 \mathrm{~A}$ and $2 \mathrm{~B}$ domains may play a greater role in the higher-order packing interactions needed to form mature IFs $[14,16,48,49]$. In our analysis of the keratin 1B mutants, we considered: (1) What interface do the mutations affect, and (2) what do the mutations do to the molecular surface chemistry of the keratin?

Structural modeling indicates that some keratin 1B mutations harm the heterodimer interface

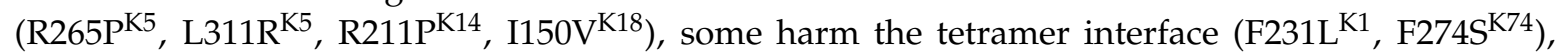
and some harm higher-order interactions needed for mature IF formation $\left(\mathrm{S} 233 \mathrm{~L}^{\mathrm{K} 1}, \mathrm{~L}_{111 \mathrm{R}^{\mathrm{K}} 5}, \mathrm{Q} 169 \mathrm{E}^{\mathrm{K}}\right.$, $\mathrm{H} 128 \mathrm{~L}^{\mathrm{K} 18}$ ). Some mutations, like $\mathrm{L} 311 \mathrm{R}^{\mathrm{K} 5}$, alter multiple interfaces. Three of the $1 \mathrm{~B}$ mutations have a prominent change in molecular surface properties: $\mathrm{Q} 169 \mathrm{E}^{\mathrm{K} 8}$ generates an acidic surface patch, $\mathrm{L} 311 \mathrm{R}^{\mathrm{K} 5}$ eliminates a hydrophobic patch, and $\mathrm{H} 128 \mathrm{~L}^{\mathrm{K} 18}$ creates a new hydrophobic patch. Solvent accessible hydrophobic surface has been shown to cause aberrant aggregation for S233 $\mathrm{L}^{\mathrm{K} 1}$ [16], leading to dramatic morphological change from tonofilaments to tonotubules [24]. H128L $\mathrm{L}^{\mathrm{K} 18}$ altered K8/K18 IFs in vitro by electron microscopy [39], likely due to aberrant hydrophobic interactions. Importantly, our analysis demonstrated structural changes conducive to IF pathology even for the three missense mutations $\left(\mathrm{Q} 169 \mathrm{E}^{\mathrm{K} 8}, \mathrm{H} 128 \mathrm{~L}^{\mathrm{K} 18}, \mathrm{I} 150 \mathrm{~V}^{\mathrm{K} 18}\right)$ allocated a "benign" prediction by Polyphen-2 analysis (Table 1). This indicates that primary sequence analysis alone is not sufficient to capture the pathogenicity of a keratin mutation, and that analysis of keratin structure plays an essential role in understanding the molecular basis of disease.

The molecular modeling presented here establishes a foundation for designing future biochemical studies to validate the predicted amino acid properties of these keratin mutations. While the modeling is in silico, this computational structural biology is based on an experimentally derived keratin 1/10 tetrameric crystal structure, and thus is more reliable than ab initio structure prediction. The analysis of pathogenic $\mathrm{K} 1$ mutations mapped onto the $1 \mathrm{~B}$ structure advances our knowledge of how disease-causing keratin mutations alter the various stages of mature filament assembly.

Ultimately, each pathologic keratin mutation will exhibit its own "structurotype" or set of biochemical and structural changes driving pathogenesis. Identifying the molecular parameters of a keratin mutation is the initial step toward the goal of being able to manipulate keratin IFs for pharmacological purposes [50]. As the number of experimental keratin structures grows, so will the insights into the molecular mechanisms driving mature filament assembly. This knowledge is essential for understanding IF-related diseases and developing new approaches to treat keratinopathies.

\section{Materials and Methods}

Keratin primary sequences, mutations, and corresponding literature were identified using the HIFD (interfil.org) [6] and cross-referenced using the UniProt [51] and National Center for Biotechnology Information (NCBI) variant databases: dbSNP [52] and ClinVar [53]. NCBI Protein Accession Numbers for each keratin analyzed were: K1: NP_006112.3, K10: NP_000412.3, K5: NP_000415.2, K14: NP_000517.2, K8: NP_002264.1, K18: NP_000215.1, K74: NP_778223.2, K28: NP_853513.2. Polyphen-2 was used to assess mutation severity [22]. Clustal Omega was used to perform multiple sequence alignments [54]. Homology modeling was performed with SWISS-MODEL [55] using the K1(S233L)/K10-1B tetramer structure (PDB ID 6E2J) as a template [16]. Coot [56] and UCSF Chimera [57] were used for energy minimization, structure analysis, and figure preparation. Final figures were made using Adobe Illustrator. 
Author Contributions: Conceptualization, C.G.B.; Data curation, A.J.H.; Formal analysis, C.G.B.; Funding acquisition, C.G.B.; Investigation, C.G.B. and A.J.H.; Validation, S.A.E. and M.H.; Writing-original draft, A.J.H.; Writing-review \& editing, S.A.E., M.H. and C.G.B. All authors have read and agreed to the published version of the manuscript.

Funding: This work was supported by NIH/NIAMS Awards K08AR070290 and R03AR076484 (to CGB).

Conflicts of Interest: S.A.E., M.H., and C.G.B. are inventors on pending patent PCT/US19/55115.

\section{Abbreviations}

IF

K Keratin

EBS Epidermolysis bullosa simplex

EPPK Epidermolytic palmoplantar keratoderma

PDB Protein Data Bank

HIFD Human Intermediate Filament Database

MALS Multi-angle light scattering

PHNED Pure hair and nail ectodermal dysplasia

NEPPK Non-epidermolytic palmoplantar keratoderma

GFAP Glial fibrillary acidic protein

NCBI National Center for Biotechnology Information

\section{References}

1. Ku, N.O.; Zhou, X.; Toivola, D.M.; Omary, M.B. The cytoskeleton of digestive epithelia in health and disease. Am. J. Physiol. 1999, 277, 1108-1137. [CrossRef] [PubMed]

2. Herrmann, H.; Bär, H.; Kreplak, L.; Strelkov, S.V.; Aebi, U. Intermediate filaments: From cell architecture to nanomechanics. Nat. Rev. Mol. Cell. Biol. 2007, 8, 562-573. [CrossRef] [PubMed]

3. Coulombe, P.A.; Fuchs, E. Elucidating the early stages of keratin filament assembly. J. Cell. Biol. 1990, 111, 153-169. [CrossRef] [PubMed]

4. Jacob, J.T.; Coulombe, P.A.; Kwan, R.; Omary, M.B. Types I and II Keratin Intermediate Filaments. Cold Spring Harb. Perspect. Biol. 2018, 10, a018275. [CrossRef]

5. Omary, M.B. "IF-pathies": A broad spectrum of intermediate filament-associated diseases. J. Clin. Investig. 2009, 119, 1756-1762. [CrossRef]

6. Szeverenyi, I.; Cassidy, A.J.; Chung, C.W.; Lee, B.T.; Common, J.E.; Ogg, S.C.; Chen, H.; Sim, S.Y.; Goh, W.L.; $\mathrm{Ng}$, K.W.; et al. The Human Intermediate Filament Database: Comprehensive information on a gene family involved in many human diseases. Hum. Mutat. 2008, 29, 351-360. [CrossRef]

7. Toivola, D.M.; Boor, P.; Alam, C.; Strnad, P. Keratins in health and disease. Curr. Opin. Cell. Biol. 2015, 32, 73-81. [CrossRef]

8. Steinert, P.M.; Bale, S.J. Genetic skin diseases caused by mutations in keratin intermediate filaments. Trends Genet. 1993, 9, 280-284. [CrossRef]

9. Jones, L.N.; Steinert, P.M. Hair keratinization in health and disease. Dermatol. Clin. 1996, 14, 633-650. [CrossRef]

10. Chamcheu, J.C.; Siddiqui, I.A.; Syed, D.N.; Adhami, V.M.; Liovic, M.; Mukhtar, H. Keratin gene mutations in disorders of human skin and its appendages. Arch. Biochem. Biophys. 2011, 508, 123-137. [CrossRef]

11. Karantza, V. Keratins in health and cancer: More than mere epithelial cell markers. Oncogene 2011, 30, 127-138. [CrossRef] [PubMed]

12. Bunick, C.G.; Milstone, L.M. The X-ray Crystal Structure of the Keratin 1-Keratin 10 Helix 2B Heterodimer Reveals Molecular Surface Properties and Biochemical Insights into Human Skin Disease. J. Investig. Dermatol. 2017, 137, 142-150. [CrossRef] [PubMed]

13. Lee, C.H.; Kim, M.S.; Chung, B.M.; Leahy, D.J.; Coulombe, P.A. Structural basis for heteromeric assembly and perinuclear organization of keratin filaments. Nat. Struct. Mol. Biol. 2012, 19, 707-715. [CrossRef] [PubMed]

14. Lomakin, I.B.; Hinbest, A.J.; Ho, M.; Eldirany, S.A.; Bunick, C.G. Crystal structure of keratin 1/10(C401A) 2B heterodimer demonstrates a proclivity for the $\mathrm{C}$-terminus of helix $2 \mathrm{~B}$ to form higher order molecular contacts. Yale J. Biol. Med. 2020, 93, 3-17. [PubMed] 
15. Eldirany, S.A.; Ho, M.; Bunick, C.G. The Interface between Keratin Structurotype and Human Disease. Structure 2020, 28, 271-273. [CrossRef] [PubMed]

16. Eldirany, S.A.; Ho, M.; Hinbest, A.J.; Lomakin, I.B.; Bunick, C.G. Human keratin 1/10-1B tetramer structures reveal a knob-pocket mechanism in intermediate filament assembly. EMBO J. 2019, 38, e100741. [CrossRef]

17. Kim, B.; Kim, S.; Jin, M.S. Crystal structure of the human glial fibrillary acidic protein 1B domain. Biochem. Biophys. Res. Commun. 2018, 503, 2899-2905. [CrossRef]

18. Aziz, A.; Hess, J.F.; Budamagunta, M.S.; Voss, J.C.; Kuzin, A.P.; Huang, Y.J.; Xiao, R.; Montelione, G.T.; FitzGerald, P.G.; Hunt, J.F. The structure of vimentin linker 1 and rod 1B domains characterized by site-directed spin-labeling electron paramagnetic resonance (SDSL-EPR) and X-ray crystallography. J. Biol. Chem. 2012, 287, 28349-28361. [CrossRef]

19. Pang, A.H.; Obiero, J.M.; Kulczyk, A.W.; Sviripa, V.M.; Tsodikov, O.V. A crystal structure of coil 1B of vimentin in the filamentous form provides a model of a high-order assembly of a vimentin filament. FEBS J. 2018, 285, 2888-2899. [CrossRef]

20. Lilina, A.V.; Chernyatina, A.A.; Guzenko, D.; Strelkov, S.V. Lateral A. J. Struct. Biol. 2020, $209,107404$. [CrossRef]

21. Ahn, J.; Jo, I.; Kang, S.M.; Hong, S.; Kim, S.; Jeong, S.; Kim, Y.H.; Park, B.J.; Ha, N.C. Structural basis for lamin assembly at the molecular level. Nat. Commun. 2019, 10, 3757. [CrossRef]

22. Adzhubei, I.; Jordan, D.M.; Sunyaev, S.R. Predicting functional effect of human missense mutations using PolyPhen-2. Curr. Protoc. Hum. Genet. 2013, 76, 7.20.1-7.20.41. [CrossRef] [PubMed]

23. Grimberg, G.; Hausser, I.; Müller, F.B.; Wodecki, K.; Schaffrath, C.; Krieg, T.; Oji, V.; Traupe, H.; Arin, M.J. Novel and recurrent mutations in the $1 \mathrm{~B}$ domain of keratin 1 in palmoplantar keratoderma with tonotubules. Br. J. Dermatol. 2009, 160, 446-449. [CrossRef]

24. Terron-Kwiatkowski, A.; van Steensel, M.A.; van Geel, M.; Lane, E.B.; McLean, W.H.; Steijlen, P.M. Mutation S233L in the 1B domain of keratin 1 causes epidermolytic palmoplantar keratoderma with "tonotubular" keratin. J. Investig. Dermatol. 2006, 126, 607-613. [CrossRef] [PubMed]

25. Hotz, A.; Oji, V.; Bourrat, E.; Jonca, N.; Mazereeuw-Hautier, J.; Betz, R.C.; Blume-Peytavi, U.; Stieler, K.; Morice-Picard, F.; Schonbuchner, I.; et al. Expanding the Clinical and Genetic Spectrum of KRT1, KRT2 and KRT10 Mutations in Keratinopathic Ichthyosis. Acta Derm. Venereol. 2016, 96, 473-478. [CrossRef]

26. Kang, T.W.; Lee, J.S.; Kim, S.E.; Oh, S.W.; Kim, S.C. Novel and recurrent mutations in Keratin 5 and 14 in Korean patients with Epidermolysis bullosa simplex. J. Dermatol. Sci. 2010, 57, 90-94. [CrossRef]

27. Ciubotaru, D.; Bergman, R.; Baty, D.; Indelman, M.; Pfendner, E.; Petronius, D.; Moualem, H.; Kanaan, M.; Ben Amitai, D.; McLean, W.H.; et al. Epidermolysis bullosa simplex in Israel: Clinical and genetic features. Arch. Dermatol. 2003, 139, 498-505. [CrossRef] [PubMed]

28. Strnad, P.; Kucukoglu, O.; Lunova, M.; Guldiken, N.; Lienau, T.C.; Stickel, F.; Omary, M.B. Non-coding keratin variants associate with liver fibrosis progression in patients with hemochromatosis. PLOS ONE 2012, 7, e32669. [CrossRef]

29. Gutierrez, J.A.; Hannoush, Z.C.; Vargas, L.G.; Momany, A.; Garcia, C.C.; Murray, J.C.; Dunnwald, M. A Novel non-sense Mutation in Keratin 10 Causes a Familial Case of Recessive Epidermolytic Ichthyosis. Mol. Genet. Genom. Med. 2013, 1, 108-112. [CrossRef] [PubMed]

30. Jonkman, M.F.; Heeres, K.; Pas, H.H.; van Luyn, M.J.; Elema, J.D.; Corden, L.D.; Smith, F.J.; McLean, W.H.; Ramaekers, F.C.; Burton, M.; et al. Effects of keratin 14 ablation on the clinical and cellular phenotype in a kindred with recessive epidermolysis bullosa simplex. J. Investig. Dermatol. 1996, 107, 764-769. [CrossRef]

31. Schuilenga-Hut, P.H.; Scheffer, H.; Pas, H.H.; Nijenhuis, M.; Buys, C.H.; Jonkman, M.F. Partial revertant mosaicism of keratin 14 in a patient with recessive epidermolysis bullosa simplex. J. Investig. Dermatol. 2002, 118, 626-630. [CrossRef] [PubMed]

32. Hut, P.H.; Vlies, P.v.d.; Jonkman, M.F.; Verlind, E.; Shimizu, H.; Buys, C.H.; Scheffer, H. Exempting homologous pseudogene sequences from polymerase chain reaction amplification allows genomic keratin 14 hotspot mutation analysis. J. Investig. Dermatol. 2000, 114, 616-619. [CrossRef] [PubMed]

33. Chan, Y.; Anton-Lamprecht, I.; Yu, Q.C.; Jackel, A.; Zabel, B.; Ernst, J.P.; Fuchs, E. A human keratin 14 "knockout": The absence of K14 leads to severe epidermolysis bullosa simplex and a function for an intermediate filament protein. Genes Dev. 1994, 8, 2574-2587. [CrossRef] [PubMed] 
34. Yiasemides, E.; Trisnowati, N.; Su, J.; Dang, N.; Klingberg, S.; Marr, P.; Melbourne, W.; Tran, K.; Chow, C.W.; Orchard, D.; et al. Clinical heterogeneity in recessive epidermolysis bullosa due to mutations in the keratin 14 gene, KRT14. Clin. Exp. Dermatol. 2008, 33, 689-697. [CrossRef]

35. Müller, F.B.; Küster, W.; Wodecki, K.; Almeida, H.; Bruckner-Tuderman, L.; Krieg, T.; Korge, B.P.; Arin, M.J. Novel and recurrent mutations in keratin KRT5 and KRT14 genes in epidermolysis bullosa simplex: Implications for disease phenotype and keratin filament assembly. Hum. Mutat. 2006, 27, 719-720. [CrossRef]

36. Bolling, M.C.; Lemmink, H.H.; Jansen, G.H.L.; Jonkman, M.F. Mutations in KRT5 and KRT14 cause epidermolysis bullosa simplex in 75\% of the patients. Br. J. Dermatol. 2011, 164, 637-644. [CrossRef]

37. Lanschuetzer, C.M.; Klausegger, A.; Pohla-Gubo, G.; Hametner, R.; Richard, G.; Uitto, J.; Hintner, H.; Bauer, J.W. A novel homozygous nonsense deletion/insertion mutation in the keratin 14 gene (Y248X; 744delC/insAG) causes recessive epidermolysis bullosa simplex type Köbner. Clin. Exp. Dermatol. 2003, 28, 77-79. [CrossRef]

38. García, M.; Santiago, J.L.; Terron, A.; Hernandez-Martin, A.; Vicente, A.; Fortuny, C.; De Lucas, R.; Lopez, J.C.; Cuadrado-Corrales, N.; Holguin, A.; et al. Two novel recessive mutations in KRT14 identified in a cohort of 21 Spanish families with epidermolysis bullosa simplex. Br. J. Dermatol. 2011, 165, 683-692. [CrossRef]

39. Ku, N.O.; Wright, T.L.; Terrault, N.A.; Gish, R.; Omary, M.B. Mutation of human keratin 18 in association with cryptogenic cirrhosis. J. Clin. Investig. 1997, 99, 19-23. [CrossRef]

40. Ku, N.O.; Lim, J.K.; Krams, S.M.; Esquivel, C.O.; Keeffe, E.B.; Wright, T.L.; Parry, D.A.; Omary, M.B. Keratins as susceptibility genes for end-stage liver disease. Gastroenterology 2005, 129, 885-893. [CrossRef]

41. Raykova, D.; Klar, J.; Azhar, A.; Khan, T.N.; Malik, N.A.; Iqbal, M.; Tariq, M.; Baig, S.M.; Dahl, N. Autosomal recessive transmission of a rare KRT74 variant causes hair and nail ectodermal dysplasia: Allelism with dominant woolly hair/hypotrichosis. PLoS ONE 2014, 9, e93607. [CrossRef]

42. Wevers, A.; Kuhn, A.; Mahrle, G. Palmoplantar keratoderma with tonotubular keratin. J. Am. Acad. Dermatol. 1991, 24, 638-642. [CrossRef]

43. Woolfson, D.N.; Williams, D.H. The influence of proline residues on alpha-helical structure. FEBS Lett. 1990, 277, 185-188. [CrossRef]

44. Strnad, P.; Paschke, S.; Jang, K.H.; Ku, N.O. Keratins: Markers and modulators of liver disease. Curr. Opin. Gastroenterol. 2012, 28, 209-216. [CrossRef]

45. Ku, N.O.; Darling, J.M.; Krams, S.M.; Esquivel, C.O.; Keeffe, E.B.; Sibley, R.K.; Lee, Y.M.; Wright, T.L.; Omary, M.B. Keratin 8 and 18 mutations are risk factors for developing liver disease of multiple etiologies. Proc. Natl. Acad. Sci. USA. 2003, 100, 6063-6068. [CrossRef]

46. Shimomura, Y.; Wajid, M.; Petukhova, L.; Kurban, M.; Christiano, A.M. Autosomal-dominant woolly hair resulting from disruption of keratin 74 (KRT74), a potential determinant of human hair texture. Am. J. Hum. Genet. 2010, 86, 632-638. [CrossRef]

47. Langbein, L.; Rogers, M.A.; Praetzel-Wunder, S.; Helmke, B.; Schirmacher, P.; Schweizer, J. K25 (K25irs1), K26 (K25irs2), K27 (K25irs3), and K28 (K25irs4) represent the type I inner root sheath keratins of the human hair follicle. J. Investig. Dermatol. 2006, 126, 2377-2386. [CrossRef]

48. Lee, C.H.; Kim, M.S.; Li, S.; Leahy, D.J.; Coulombe, P.A. Structure-Function Analyses of a Keratin Heterotypic Complex Identify Specific Keratin Regions Involved in Intermediate Filament Assembly. Structure 2020, 28, 355-362. [CrossRef]

49. Bernot, K.M.; Lee, C.H.; Coulombe, P.A. A small surface hydrophobic stripe in the coiled-coil domain of type I keratins mediates tetramer stability. J. Cell. Biol. 2005, 168, 965-974. [CrossRef]

50. Sun, J.; Groppi, V.E.; Gui, H.; Chen, L.; Xie, Q.; Liu, L.; Omary, M.B. High-Throughput Screening for Drugs that Modulate Intermediate Filament Proteins. Methods Enzymol. 2016, 568, 163-185. [CrossRef]

51. Consortium, U. UniProt: A worldwide hub of protein knowledge. Nucleic Acids Res. 2019, 47, D506-D515. [CrossRef]

52. Sherry, S.T.; Ward, M.; Sirotkin, K. dbSNP-database for single nucleotide polymorphisms and other classes of minor genetic variation. Genome Res. 1999, 9, 677-679.

53. Landrum, M.J.; Kattman, B.L. ClinVar at five years: Delivering on the promise. Hum. Mutat. 2018, 39, 1623-1630. [CrossRef]

54. Sievers, F.; Wilm, A.; Dineen, D.; Gibson, T.J.; Karplus, K.; Li, W.; Lopez, R.; McWilliam, H.; Remmert, M.; Söding, J.; et al. Fast, scalable generation of high-quality protein multiple sequence alignments using Clustal Omega. Mol. Syst. Biol. 2011, 7, 539. [CrossRef] 
55. Waterhouse, A.; Bertoni, M.; Bienert, S.; Studer, G.; Tauriello, G.; Gumienny, R.; Heer, F.T.; de Beer, T.A.P.; Rempfer, C.; Bordoli, L.; et al. SWISS-MODEL: Homology modelling of protein structures and complexes. Nucleic Acids Res. 2018, 46, W296-W303. [CrossRef]

56. Emsley, P.; Cowtan, K. Coot: Model-building tools for molecular graphics. Acta Crystallogr. D Biol. Crystallogr. 2004, 60, 2126-2132. [CrossRef]

57. Pettersen, E.F.; Goddard, T.D.; Huang, C.C.; Couch, G.S.; Greenblatt, D.M.; Meng, E.C.; Ferrin, T.E. UCSF Chimera-A visualization system for exploratory research and analysis. J. Comput. Chem. 2004, 25, 1605-1612. [CrossRef]

(C) 2020 by the authors. Licensee MDPI, Basel, Switzerland. This article is an open access article distributed under the terms and conditions of the Creative Commons Attribution (CC BY) license (http://creativecommons.org/licenses/by/4.0/). 